\title{
An occurence records database of French Guiana harvestmen (Arachnida, Opiliones)
}

\author{
Sébastien Cally ${ }^{\dagger}$, Pierre Solbès ${ }^{\dagger},{\text { Bernadette } \text { Grosso }^{\dagger} \text {, Jérôme Murienne }}^{\dagger}$ \\ † UMR5174 CNRS/UPS/ENFA, Toulouse, France
}

Corresponding author: Sébastien Cally (sebastien.cally@univ-tlse3.fr), Jérôme Murienne (jerome.murienne@univ-tlse3.fr)

Academic editor: Adriano Kury

Received: 13 Nov 2014 | Accepted: 21 Dec 2014 | Published: 25 Dec 2014

Citation: Cally S, Solbès P, Grosso B, Murienne J (2014) An occurence records database of French Guiana

harvestmen (Arachnida, Opiliones). Biodiversity Data Journal 2: e4244. doi: 10.3897/BDJ.2.e4244

\section{Abstract}

This dataset provides information on specimens of harvestmen (Arthropoda, Arachnida, Opiliones) collected in French Guiana. Field collections have been initiated in 2012 within the framework of the CEnter for the Study of Biodiversity in Amazonia (CEBA: www.labexceba.fr/en/). This dataset is a work in progress. Occurrences are recorded in an online database stored at the EDB laboratory after each collecting trip and the dataset is updated on a monthly basis. Voucher specimens and associated DNA are also stored at the EDB laboratory until deposition in natural history Museums. The latest version of the dataset is publicly and freely accessible through our Integrated Publication Toolkit at http://130.120.204.55:8080/ipt/resource.do?r=harvestmen of french guiana or through the Global Biodiversity Information Facility data portal at http://www.gbif.org/ dataset/3c9e2297-bf20-4827-928e-7c7eefd9432c.

\section{Keywords}

Occurrence, French Guiana, Neotropics, Opiliones. 


\section{Introduction}

French Guiana is a French overseas department covered at $97 \%$ by primary forest (Gond et al. 2011). As such, it represents the only Outermost Region of Europe covering a large fraction of mainland in tropical South America. The territory is part of the Guianan moist forests ecoregion and has strong biogeographic affinities with the rest of the Amazonia bioregion (Olson et al. 2001). The biological diversity of French Guiana is now one of the best known in South America, yet some gaps in knowledge still exist, especially in arthropods.

With more than 6500 species, harvestmen (Opiliones) is the third most diverse order of arachnid after Acari and Araneae (Kury 2013). They occur in superficial soil layers, leaf litter, under bark, and on vegetation from ground to canopy (Pinto-da-Rocha and Bonaldo 2006). The maximum richness of harvestmen species is found in the Neotropical region, however, diversity patterns within this region are still poorly known, both on regional and local scales. Because of their relatively high abundance and diversity in the Neotropical forests, they are useful candidates for studying community ecology (e.g. Proud et al. 2012), phylogeography, and biogeography (e.g. Sharma and Giribet 2012).

By providing a database on harvestmen of French Guiana, regularly updated and publicly available, our goal is to provide a fast and efficient tool for sharing and tracking information on collected specimens. This database will be used for disseminating biodiversity information related to ongoing work on ecology and evolution of harvestmen in French Guiana. We also aim to promote best practices for recording and sharing biodiversity data within our research community. We believe this will make a valuable contribution to the global effort of sharing harvestmen database information (e.g. Merino-Sáinz et al. 2013).

\section{Project description}

Title: Harvestmen of French Guiana

Personel: Jérôme Murienne

Study area description: Collecting trips have been conducted in various locations throughout French Guiana.

Design description: This dataset was developed to determine the current distribution patterns of harvestmen species at the scale of French Guiana. Thus locations to be sampled were selected to maximize the geographical coverage. For some collecting trips (e.g. Saül 2013), a specific design was implemented to sample over three topographic units: hilltop, slope and seasonally-flooded bottomland.

Funding: Data for this resource have been obtained within the framework of grants DIADEMA and PHYLOGUIANAS from the Labex CEBA (Laboratoire d'Excellence Center for the Study of Biodiversity in Amazonia). CEBA is funded by "Investissement d'Avenir" 
grant managed by the French National Research Agency (ANR) under grant number ANR-10-LABX-25-CEBA.

\section{Sampling methods}

Study extent: Study sites were located throughout French Guiana.

Sampling description: The following techniques were used, however not all techniques were used on every collecting site and sampling design might not be similar among these sites.

Pitfall traps: 20 plastic cups with $70 \%$ ethanol were distributed within a 0.5 hectare plot and exposed for 72 hours.

Winkler: all the litter and superficial soil layer from $1 \mathrm{~m}^{2}$ was concentrated with the aid of a hand-sieve and sorted using a winkler apparatus during 2 days.

Litter manual sorting: all the litter and superficial soil layer from $1 \mathrm{~m}^{2}$ was concentrated with the aid of a hand-sieve and sorted by hand using a plastic square plate.

Beating: vegetation above knee-level was sampled using a $1 \mathrm{~m}^{2}$ beating sheet.

Sweeping: vegetation below knee-level was sampled using a sweep net.

Manual nocturnal ground search: samples are collected during the night on the ground or at the base of trunks.

Manual search in and under the dead wood. Samples are collected by searching in and under the dead wood pieces or the dead trunks on the ground.

Quality control: GPS coordinates were obtained using a GPSmap 60CSx device or similar. Such devices report coordinates accuracy using the CEP50 (Circular Error Probability), meaning that there is only $50 \%$ probability that a reported position would be within a distance of $X$ meters to the real position. Considering other sources of GPS errors (such as ionosphere delay and signal multi path) we estimate the accuracy of the coordinates to be around 30 meters at a $95 \%$ confidence level.

Initial specimens identifications to the family level (for all families) and genus level (for Agoristenidae, Stygnidae and Gonyleptidae) have been checked by Ricardo Pinto-daRocha. Validity of the taxonomic names used was checked against the Encyclopedia of Life (http://www.eol.org) and the GBIF backbone taxonomy (http://www.gbif.org/dataset/ d7dddbf4-2cf0-4f39-9b2a-bb099caae36c). Future validity checks could use the "World Checklist of Opiliones species", once it is published in its entirety (Kury et al. 2014).

Step description: After collection, samples are sorted and placed in individual tubes containing $95 \%$ ethanol with a unique identifier until further processing in the laboratory. Codes are based on locality, collection date, collection method followed by a unique 
number as in GF140308HC001-07 which indicates that the specimen was collected in French Guiana (GF) on 2014-03-08 (yyyy-mm-dd), and hand collected (HC). Collection method codes include sweep net (SN, SND or SNN), beating (BND or BNN), pitfall (PT), winkler (WK, WKD or WKN). When specimen collection was part of a larger field expedition, we kept the original codes that might not follow this rule (as in SL13-1208OP01 collected in Saül).

Collecting information for each specimen is databased in an online Voseq database (Peña and Malm 2012) hosted by the EDB laboratory (Fig. 1).

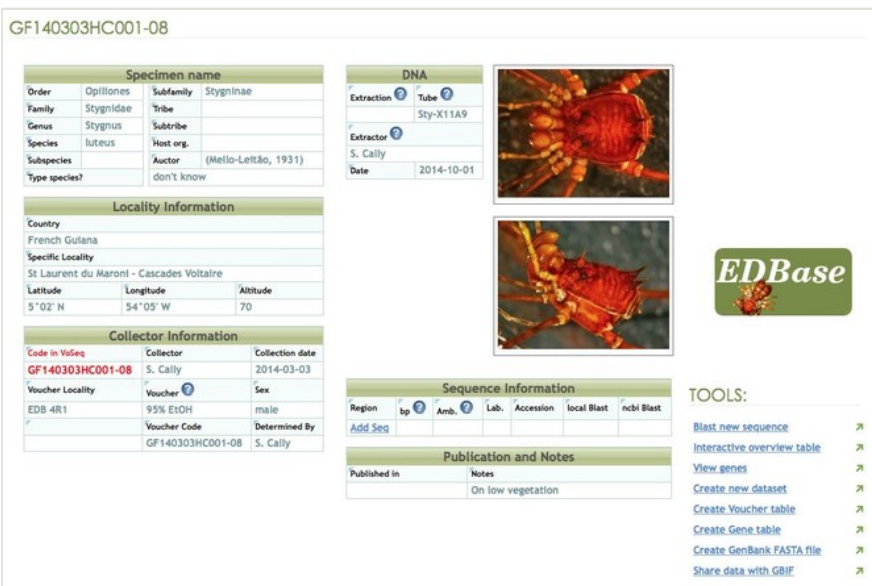

Figure 1.

Example data entry of our online database (http://edbase.ups-tlse.fr with restricted access) holding the "Harvestmen of French Guiana" dataset. The database can be downloaded as a spreadsheet at: http://130.120.204.55:8080/ipt/resource.do?r=harvestmen_of_french_guiana or at: http://www.gbif.org/dataset/3c9e2297-bf20-4827-928e-7c7eefd9432c.

Specimens are photographed using an Olympus DP20 mounted on a Leica MZ16 binocular and pictures are stored in the database.

For each specimen, 1 or 2 legs are kept in a separate vial and stored at $-20^{\circ} \mathrm{C}$ for further molecular investigation.

Specimens are initially curated at the EDB laboratory by J. Murienne and can be deposited in museums for further taxonomic study. For example, specimens of Sclerosomatidae have been sent as gift to the Museum of Comparative Zoology (MCZ) at Harvard University, Cambridge USA, to be investigated by Ana Lucia Tourinho. The current localisation of the specimens (either at EDB or in museums) can be found under the "disposition" field. 


\section{Geographic coverage}

Description: The sampling area is delimited by the current administrative boundaries of the French Guiana territory (Fig. 2). To the East, the Oyapock River delimits the frontier with Brazil. To the West, the Maroni River delimits the frontier with Surinam. This is an important detail as the delimitation of the territory has not been constant throughout history and a large portion of northern Brazil was disputed between France and Brazil during the 19th century. Several species described or reported from French Guiana during the 19th century and early 20th century (see Kury 2003) are actually located in Brazil. Even though French Guiana is an overseas department and region of France, all occurrences have been recorded under the "French Guiana" country to comply with the ISO 3166-1 standard.

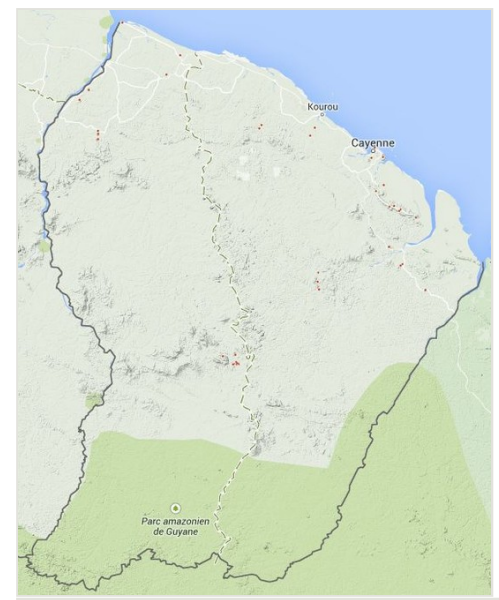

Figure 2.

Geographical coverage of the dataset and collecting localities as of 2014.

Coordinates: 2.09 and 5.85 Latitude; -51.53 and -54.61 Longitude.

\section{Taxonomic coverage}

Description: This database is devoted to all harvestmen species inhabiting French Guiana. Little is known about the taxonomy of the group in French Guiana but some information are available in Kury (2003) for Laniatores and Benavides and Giribet (2013) for Cyphophthalmi. Identifications to the family level were conducted based on Kury and Pinto-da-Rocha (2002) and Pinto-da-Rocha et al. (2007) (Fig. 3). Three families are here reported for the first time in French Guiana, namely Agoristenidae, Fissiphalliidae and Icaleptidae. Identifications of Stygnidae to the species level were conducted based on Pinto-da-Rocha (1997). 


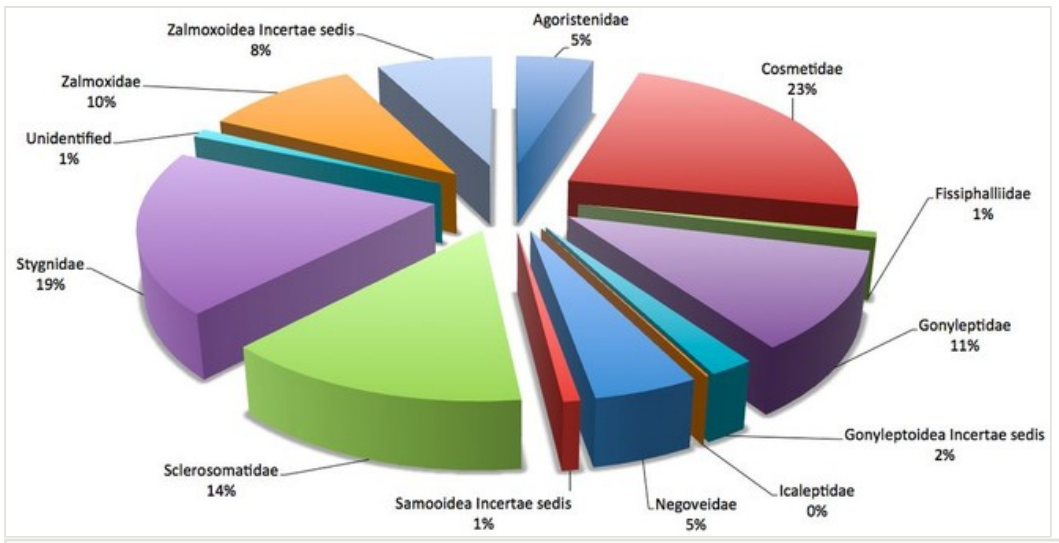

Figure 3.

Taxonomic coverage at the family level of the "Harvestmen of French Guiana" dataset as of 2014.

Taxa included:

\begin{tabular}{|l|l|}
\hline Rank & Scientific Name \\
\hline kingdom & Animalia \\
\hline phylum & Arthropoda \\
\hline class & Arachnida \\
\hline order & Opiliones \\
\hline family & Neogoveidae \\
\hline family & Sclerosomatidae \\
\hline family & Agoristenidae \\
\hline family & Stygnidae \\
\hline family & Cosmetidae \\
\hline family & Gonyleptidae \\
\hline family & Fissiphalliidae \\
\hline family & Zalmoxidae \\
\hline family & Icaleptidae \\
\hline
\end{tabular}

\section{Temporal coverage}

Notes: 2012-present

\section{Collection data}

Collection name: EDB arthropod collection

Parent collection identifier: EDB specimen collection

Specimen preservation method: Alcohol (95\%) 


\section{Usage rights}

\section{Use license: Other}

IP rights notes: This work is licensed under a Creative Commons AttributionNonCommercial 4.0 International Public License. http://creativecommons.org/licenses/by$\mathrm{nc} / 4.0 /$. Users of this resource should also comply with the CEBA data sharing agreement available here: www.labex-ceba.fr/assets/CEBA Data Sharing Agreement nov2013.pdf

\section{Data resources}

Data package title: Harvestmen of French Guiana

Resource

r=harvestmen_of_french_guiana

\section{Alternative}

bf20-4827-928e-7c7eefd9432c

\section{Number of data sets: 1}

Data set name: Harvestmen of French Guiana

\section{Character set: UTF-8}

Data format: Darwin Core Archive format

\section{Data format version: 1.0}

\begin{tabular}{|c|c|}
\hline Column label & Column description \\
\hline occurrencelD & $\begin{array}{l}\text { An identifier for the Occurrence (as opposed to a particular digital record of the } \\
\text { occurrence). In the absence of a persistent global unique identifier, construct one } \\
\text { from a combination of identifiers in the record that will most closely make the } \\
\text { occurrencelD globally unique. See also http://rs.tdwg.org/dwc/terms/ } \\
\text { index.htm\#occurrencelD For line numbers you can specify an optional non-numerical } \\
\text { suffix to be appended to the id. This is useful to generate unique identifiers when } \\
\text { mapping the same source multiple times. }\end{array}$ \\
\hline institutionCode & $\begin{array}{l}\text { The name (or acronym) in use by the institution having custody of the object(s) or } \\
\text { information referred to in the record. }\end{array}$ \\
\hline collectionCode & $\begin{array}{l}\text { The name, acronym, coden, or initialism identifying the collection or data set from } \\
\text { which the record was derived. }\end{array}$ \\
\hline basisOfRecord & $\begin{array}{l}\text { The specific nature of the data record - a subtype of the dcterms:type. } \\
\text { Recommended best practice is to use a controlled vocabulary such as the Darwin } \\
\text { Core Type Vocabulary (http://rs.tdwg.org/dwc/terms/type-vocabulary/index.htm). }\end{array}$ \\
\hline catalogNumber & An identifier (preferably unique) for the record within the data set or collection. \\
\hline occurrenceRemarks & Comments or notes about the Occurrence. \\
\hline recordedBy & $\begin{array}{l}\text { A list (concatenated and separated) of names of people, groups, or organizations } \\
\text { responsible for recording the original Occurrence. The primary collector or observer, } \\
\text { especially one who applies a personal identifier (recordNumber), should be listed } \\
\text { first. }\end{array}$ \\
\hline sex & $\begin{array}{l}\text { The sex of the biological individual(s) represented in the Occurrence. Recommended } \\
\text { best practice is to use a controlled vocabulary. }\end{array}$ \\
\hline preparations & $\begin{array}{l}\text { A list (concatenated and separated) of preparations and preservation methods for a } \\
\text { specimen. }\end{array}$ \\
\hline
\end{tabular}




\begin{tabular}{|c|c|}
\hline disposition & $\begin{array}{l}\text { The current state of a specimen with respect to the collection identified in } \\
\text { collectionCode or collectionID. Recommended best practice is to use a controlled } \\
\text { vocabulary. }\end{array}$ \\
\hline otherCatalogNumbers & $\begin{array}{l}\text { A list (concatenated and separated) of previous or alternate fully qualified catalog } \\
\text { numbers or other human-used identifiers for the same Occurrence, whether in the } \\
\text { current or any other data set or collection. }\end{array}$ \\
\hline associatedMedia & $\begin{array}{l}\text { A list (concatenated and separated) of identifiers (publication, global unique identifier, } \\
\text { URI) of media associated with the Occurrence. }\end{array}$ \\
\hline associatedReferences & $\begin{array}{l}\text { A list (concatenated and separated) of identifiers (publication, bibliographic } \\
\text { reference, global unique identifier, URI) of literature associated with the Occurrence. }\end{array}$ \\
\hline associatedTaxa & $\begin{array}{l}\text { A list (concatenated and separated) of identifiers or names of taxa and their } \\
\text { associations with the Occurrence. }\end{array}$ \\
\hline eventDate & $\begin{array}{l}\text { The date-time or interval during which an Event occurred. For occurrences, this is } \\
\text { the date-time when the event was recorded. Not suitable for a time in a geological } \\
\text { context. Recommended best practice is to use an encoding scheme, such as ISO } \\
8601: 2004(E) \text {. }\end{array}$ \\
\hline country & The name of the country or major administrative unit in which the Location occurs. \\
\hline locality & $\begin{array}{l}\text { The specific description of the place. Less specific geographic information can be } \\
\text { provided in other geographic terms (higherGeography, continent, country, } \\
\text { stateProvince, county, municipality, waterBody, island, islandGroup). This term may } \\
\text { contain information modified from the original to correct perceived errors or } \\
\text { standardize the description. }\end{array}$ \\
\hline verbatimLocality & The original textual description of the place. \\
\hline verbatimElevation & $\begin{array}{l}\text { The original description of the elevation (altitude, usually above sea level) of the } \\
\text { Location. }\end{array}$ \\
\hline decimalLatitude & $\begin{array}{l}\text { The geographic latitude (in decimal degrees, using the spatial reference system } \\
\text { given in geodeticDatum) of the geographic center of a Location. Positive values are } \\
\text { north of the Equator, negative values are south of it. Legal values lie between - } 90 \\
\text { and } 90 \text {, inclusive. }\end{array}$ \\
\hline decimalLongitude & $\begin{array}{l}\text { The geographic longitude (in decimal degrees, using the spatial reference system } \\
\text { given in geodeticDatum) of the geographic center of a Location. Positive values are } \\
\text { east of the Greenwich Meridian, negative values are west of it. Legal values lie } \\
\text { between }-180 \text { and } 180 \text {, inclusive. }\end{array}$ \\
\hline identifiedBy & $\begin{array}{l}\text { A list (concatenated and separated) of names of people, groups, or organizations } \\
\text { who assigned the Taxon to the subject. }\end{array}$ \\
\hline scientificName & $\begin{array}{l}\text { The full scientific name, with authorship and date information if known. When forming } \\
\text { part of an Identification, this should be the name in lowest level taxonomic rank that } \\
\text { can be determined. This term should not contain identification qualifications, which } \\
\text { should instead be supplied in the IdentificationQualifier term. }\end{array}$ \\
\hline order & The full scientific name of the order in which the taxon is classified. \\
\hline family & The full scientific name of the family in which the taxon is classified. \\
\hline genus & The full scientific name of the genus in which the taxon is classified. \\
\hline specificEpithet & The name of the first or species epithet of the scientificName. \\
\hline infraspecificEpithet & $\begin{array}{l}\text { The name of the lowest or terminal infraspecific epithet of the scientificName, } \\
\text { excluding any rank designation. }\end{array}$ \\
\hline scientificNameAuthorship & $\begin{array}{l}\text { The authorship information for the scientificName formatted according to the } \\
\text { conventions of the applicable nomenclaturalCode. }\end{array}$ \\
\hline
\end{tabular}




\section{Acknowledgements}

The authors would like to thank the organizers of logistical support for the field missions (C. Baraloto, A. Fouquet, Parc Amazonien de Guyane, CNRS Guyane), all the contributors that helped collecting samples in the field during the CEBA missions (V. Vedel, A. Cerdan, J. Orivel and J. Donald) as well as those who kindly provided us specimens (A. Fouquet, C. Duplais, J.-P. Vacher, P.O. Cochard, M. Berroneau, L. Barthe, J. Pétillon and A. Lorenzini) and helped in species identifications (G. Giribet, A. Kury, A. Perez, R. Pinto-da-Rocha, A.L. Tourinho). We would also like to thank the GBIF France (M.-E. Lecoq and S. Pamerlon) for helping us with setting up the IPT. The EDB lab is supported by "Investissement d'Avenir" grants managed by Agence Nationale de la Recherche (CEBA: ANR-10-LABX-25-01; TULIP: ANR-10-LABX-41, ANR-11-IDEX-0002-02). Finally we greatly thank A. Kury, D. Proud and $C$. Richart for improving the manuscript.

\section{References}

- Benavides L, Giribet G (2013) A revision of selected clades of Neotropical Mite Harvestmen (Arachnida, Opiliones, Cyphophthalmi, Neogoveidae) with the description of eight new species. Bulletin of the Museum of Comparative Zoology 161 (1): 1-44. DOI: $10.3099 / 0027-4100-161.1 .1$

- Gond V, Freycon V, Molino J, Brunaux O, Ingrassia F, Joubert P, Pekel J, Prévost M, Thierron V, Trombe P, Sabatier D (2011) Broad-scale spatial pattern of forest landscape types in the Guiana Shield. International Journal of Applied Earth Observation and Geoinformation 13: 357-367. DOI: 10.1016/j.jag.2011.01.004

- Kury AB (2003) Annotated catalogue of the Laniatores of the New World (Arachnida, Opiliones). Revista Ibérica de Arachnologia 1: 5-337.

- Kury AB (2013) Order Opiliones Sundevall, 1833. Zootaxa 3703 (1): 27-33. DOI: 10.11646/zootaxa.3703.1.7

- Kury AB, Pinto-da-Rocha R (2002) Opiliones. In: Adis J (Ed.) Amazonian Arachnida and Myriapoda.

- $\quad$ Kury AB, Mendes A, Souza D (2014) World Checklist of Opiliones species (Arachnida). Part 1: Laniatores - Travunioidea and Triaenonychoidea. Biodiversity Data Journal 2: e4094. DOI: $10.3897 /$ bdj.2.e4094

- Merino-Sáinz I, Anadón A, Torralba-Burrial A (2013) Harvestmen of the BOS Arthropod Collection of the University of Oviedo (Spain) (Arachnida, Opiliones). ZooKeys 341: 21-36. DOI: $10.3897 /$ zookeys.341.6130

- Olson DM, Dinerstein E, Wikramanayake ED, Burgess ND, Powell GVN, Underwood EC, D'Amico JA, Itoua I, Strand HE, Morrison JC, Loucks CJ, Allnutt TF, Ricketts TH, Kura Y, Lamoreux JF, Wettengel WW, Hedao P, Kassem KR (2001) Terrestrial ecoregions of the world: a new map of life on Earth. Bioscience 51 (11): 933-938. DOI: 10.1641/0006-3568(2001)051[0933:TEOTWA]2.0.CO;2

- $\quad$ Peña C, Malm T (2012) VoSeq: a voucher and DNA sequence web application. PLoS ONE 7 (6): e39071. DOI: 10.1371/journal.pone.0039071

- $\quad$ Pinto-da-Rocha R (1997) Systematic review of the neotropical family Stygnidae (Opiliones, Laniatores, Gonyleptoidea). Arquivos de zoologia 33 (4): 163-342. 
- Pinto-da-Rocha R, Bonaldo AB (2006) A structured inventory of harvestmen (Arachnida, Opiliones) at Juruti River plateau, State of Pará, Brazil. Revista Ibérica de Aracnologia 13: $155-162$.

- $\quad$ Pinto-da-Rocha R, Machado G, Giribet G (2007) Harvestmen: the biology of Opiliones. Harvard University Press, 597 pp.

- $\quad$ Proud D, Felgenhauer B, Townsend V, Osula D, Gilmore W, Napier Z, Van Zandt P (2012) Diversity and habitat use of Neotropical Harvestmen (Arachnida: Opiliones) in a Costa Rican rainforest. ISRN Zoology 2012: 1-16. DOI: 10.5402/2012/549765

- Sharma PP, Giribet G (2012) Out of the Neotropics: Late Cretaceous colonization of Australasia by American arthropods. Proceedings of the Royal Society B: Biological Sciences 279 (1742): 3501-3509. DOI: 10.1098/rspb.2012.0675 